Satellite Symposium

\title{
The influence of food security and other social and environmental factors on diet in the National Low Income Diet and Nutrition Survey
}

\author{
B. Holmes \\ Nutritional Sciences Division, King's College London, 150 Stamford Street, London SE1 9NH, UK
}

The Low Income Diet and Nutrition Survey (LIDNS) is a national survey of diet and nutrition involving data collection from a representative sample of the $15 \%$ most-deprived households in the UK. The key stages of the survey involved a face-to-face interview, dietary data collection (using four repeat multiple-pass $24 \mathrm{~h}$ recalls), anthropometric measurements and the collection of blood samples. A total of 3728 individuals (aged $\geq 2$ years) from 2477 households were included in the final dataset. Results presented here are based on a number of social and environmental factors and their relationship with dietary intake data.

Food security can be defined as 'access by all people at all times to enough food for an active and healthy life'(1). Food security was calculated in LIDNS from responses to a series of questions known to characterise households having difficulty meeting basic food needs. Households were classified into one of three groups: (a) food secure; (b) mildly food insecure; (c) moderately or severely food insecure ${ }^{(2)}$.

The results suggested that the majority of the low-income population (71\%) lived in food-secure households, while $15 \%$ lived in mildly food insecure households and $14 \%$ lived in moderately- or severely-food-insecure households. The relationship between food security and food consumption and nutrient intake was most apparent in women aged $\geq 19$ years. Women in mildly- and moderately- or severely-foodinsecure households had a typically 'less healthy' diet than women in food-secure households indicated by their lower or higher (as appropriate) consumption of particular foods. The relationship was less clear for men and children ${ }^{(2)}$.

Analysis of the relationship between area of residence and dietary intake revealed that males and females aged $\geq 2$ years in the lowincome population living in urban areas consumed less food overall and were more likely to have lower energy and nutrient intakes for a number of vitamins and minerals than those living in suburban areas ('surburban areas' includes suburban and rural areas). Differences between these groups may partly reflect the ethnic group distribution in the areas ${ }^{(3)}$.

Of the low-income population $>80 \%$ lived in households in which the main shop used for purchasing food was a large supermarket and women in these households consumed significantly more fruit and vegetables than other women. About half the males (54\%) and females $(50 \%)$ lived in households that travelled by private car to the main food shop. Results indicated that there was a tendency for men and women who travelled to the food shop by car to have a 'healthier' $\operatorname{diet}^{(3)}$.

According to level of education, men and women aged $\geq 19$ years with less education (respondents with an education level lower than GCSE grades A-C including those with no education) tended to have a 'less healthy' diet in terms of food consumption and nutrient intake; differences were more apparent in women ${ }^{(4)}$.

LIDNS was funded by the Food Standards Agency and conducted by the National Centre for Social Research with King's College London and University College London.

1. Bickel G, Nord M, Price C, Hamilton WL \& Cook JT (2000) Guide to Measuring Household Food Security, Revised 2000. Alexandria, VA: US Department of Agriculture, Food and Nutrition Service.

2. Holmes B (2007) Food security. In The Low Income Diet and Nutrition Survey, vol. 3, pp. 201-220 [M Nelson, B Erens, B Bates, S Church and T Boshier, editors]. London: The Stationery Office.

3. Wells L (2007) Economic and environmental factors. In The Low Income Diet and Nutrition Survey, vol. 3, pp. 41-57 [M Nelson, B Erens, B Bates, S Church and T Boshier, editors]. London: The Stationery Office.

4. Speight S, Holmes B \& Wells L (2007) Social factors and food choice. In The Low Income Diet and Nutrition Survey, vol. 3, pp. 185-200 [M Nelson, B Erens, B Bates, S Church and T Boshier, editors]. London: The Stationery Office. 